\title{
The choice of insurance in the labor market
}

\author{
Michael Neugart*
}

August 2005

\begin{abstract}
Employment protection and unemployment benefits are considered as the most prominent insurance devices for workers to protect themselves against the risk of unemployment. It occurs that societies either choose a high level of employment protection relative to unemployment benefits or vice versa. This paper explains where countries locate on this trade-off. It is argued that higher coverage of voters out-of-the labor force with intra household transfers yields a politicoeconomic equilibrium with relatively high employment protection and relatively low unemployment benefits. Cross country data is presented that corroborates the outcomes of the model.
\end{abstract}

Keywords: employment protection, unemployment benefits, tradeoff, probabilistic voting model

JEL-Classification: D72, D78, H55

\footnotetext{
${ }^{*}$ Wissenschaftszentrum Berlin für Sozialforschung (WZB), Abteilung Arbeitsmarktpolitik und Beschäftigung, Reichpietschufer 50, 10785 Berlin, e-mail: neugart@wz-berlin.de, phone: +49 (0)30 25491119, FAX: +49 (0)30 25491100
} 


\section{Introduction}

A key characteristic of modern welfare states is the protection against the risk of unemployment. Two devices are essential: unemployment benefits and employment protection legislation (EPL). Cross country evidence suggests that there is a trade-off between those two insurance devices. Countries either have a relatively stringent EPL and relatively low unemployment benefit levels, or vice versa. This has, for example, been documented by Buti et al. (1998) and Boeri et al. (2004).

In this paper I argue that where countries locate on this trade-off is driven by the share of voters who are out-of-the labor force and covered by intra family transfers. In particular, it is claimed that voters who are not attached to the labor market but live in households that provide income transfers have a relatively stronger preference for EPL versus unemployment benefits. The reason is that the former institution makes the job of the household member that provides the transfers more secure, while unemployment benefits are financed via taxes that reduce the net income of the household. Parties competing for office make policy proposals taking appropriately into account the preferences of the different electoral groups. Thus, a larger group of voters out-of-the labor force covered by intra household transfers increases the weight that parties attach to the policy preferences of this group. Consequently, a relatively more stringent EPL will be the outcome of the electoral race.

Besides the positive analysis of the trade-off that the paper aims at, the issue carries policy relevance. It is often argued that in a rapidly changing world unemployment benefits is the superior insurance device to EPL as 
it does not impede labor reallocation (Bertola and Boeri (2002)). Providing insurance while minimizing detrimental effects on the efficient allocation of resources is much in the spirit of what has been coined the 'flexicurity' approach to labor market institutions (see e.g. Commission (2003)). If, however, the combination of insurance modes are stable politico-economic equilibria, reflecting preferences of voters as I argue, then institutional engineering is doomed to fail. While it might be desirable to move along the trade-off based on some welfare criterium, it is not necessarily the case that more unemployment benefits in exchange for less EPL or vice versa is a winning policy. Then, no such offer will be made to the electorate by competing parties that seek office.

There is a still small but growing literature on the political economy of labor market institutions that, so far, has analyzed EPL and unemployment benefits separately. The political economy of unemployment insurance systems has been studied by Wright (1986), Saint-Paul (1996), DiTella and MacCulloch (2002), Hassler et al. (2005) or Neugart (2005) among others. Politico-economic analyses of EPL can be found in Saint-Paul (2002) or Algan and Cahuc (2004).

As far as I can tell Boeri et al. (2004) have made the only attempt to study the choice of the two modes of insurance jointly up to now. They propose two mechanisms explaining the trade-off, one that recurs to the age composition of the electorate, and the other to the skill composition. They show that a higher discount rate lets unskilled insiders choose more EPL in exchange for lower unemployment benefits, which implies that societies with a more aged electorate will want less unemployment benefits but more 
EPL. Secondly, it is argued that cross country variation arises as the decisive voter may either be an unskilled insider with a relatively high desire for EPL or an unskilled outsider with a relatively high preference for unemployment benefits.

This paper adds an alternative but not necessarily competing explanation. I argue that voters out of the labor force living in a household that receives labor market income have a vital interest in the protection of the employed household member who provides intra family transfers. Thus, countries in which the family is a major means of income source for voters not attached to the labor market will find themselves with relatively high levels of EPL. Unemployment benefits in those countries are relatively lower as benefits have to be financed by taxes on labor income that reduce the employed voters' and consequently the families' net income. Besides providing a different mechanism for explaining the trade-off, this paper also distinguishes itself from Boeri et al. (2004) by employing a probabilistic voting model.

There is a considerable body of evidence on family transfers (see the e.g. Laitner (1997)) and also on labor supply decisions in the wake of those transfers (see e.g. McElroy (1985) or Rosenzweig and Wolpin (1993)). Not much is known, however, on how family transfers possibly affect the voting behavior of individuals and thus the choice of institutions. It has been argued that children who choose to live with their parents in order to circumvent credit constraints by intra family transfers have a vested interest in their parent's jobs being protected (see Fogli (2000)). Brugiavini et al. (2003) show that young individuals whose parents are retirees vote for a generous social security system due to the intra-family transfers that they receive. To 
the best of my knowledge, this paper is so far the only additional attempt to link family transfers to a positive analysis of labor market institutions.

The following two sections lay out the labor market model and the political decision mechanism. The results are given in section 3. Section 4 presents cross country evidence that supports the main proposition. The last section concludes.

\section{The model}

\subsection{The labor market}

Voters can be employed $E$, unemployed $U$, and out of the labor force $O$. I assume that the share of voters out-of-the labor force is exogenous. This group is completely unattached to the labor market. Employed voters can become unemployed at a rate $s(f)$ and unemployed voters can find jobs at a rate $a(f)$. I denote with $0 \leq f \leq 1$ a job protecting institution, such that in an economy without job protection legislation a job goes sour at rate $s(1)$ whereas not every job hit by an unfavorable shock is given up in a regulated economy $\left(s_{f}>0\right)$. Furthermore, job protection legislation shall reduce the number of vacancies posted so that the outflow rate declines in less flexible economies $\left(a_{f}>0\right)$.

Besides job protection, there shall be a second institution on which voters decide: unemployment benefits. In an economy with unemployment benefits, an unemployed voter shall receive a share $\delta$ of his former wage $w$, with the replacement rate fulfilling $0 \leq \delta \leq 1 .^{1}$ Duration of payment of unemployment

\footnotetext{
${ }^{1}$ Note, that for simplicity I postulate that the replacement rate does not have an influ-
} 
benefits is limited to the first period of unemployment.

Due to a constant returns to scale production technology the wage is fixed $(w=1)$. Out of his wage income a worker has to pay a tax $\tau_{t}$ which finances the unemployment benefits. In each period the government runs a balanced budget. Thus, the budget constraint for the first period writes

$$
\tau_{1} e_{1}=\delta u_{1}
$$

where the subscript denotes time $t=1$. In the steady state flows into unemployment equal flows out of unemployment so that the balanced budget constraint in equation (1) can also be written as:

$$
\tau_{1}=\frac{s(1)}{a(1)} \delta
$$

For the second period balancing the budget requires

$$
\frac{a(f)}{a(f)+s(f)} \tau_{2}=s(f) \frac{a(1)}{a(1)+s(1)} \delta,
$$

where the first term on the left hand side is the employment rate in period 2 which is multiplied with the wage $(w=1)$ and the tax in period 2 . As unemployment benefits duration is limited to one period, all those workers who were unemployed in the first period and did not find a job in the second period do not receive unemployment benefit payments anymore. Thus, what has to be financed by the unemployment benefit system is the benefit ence on the outflow rate from unemployment $\left(a_{\delta}=0\right)$, even though one might argue that search intensities of unemployed workers are a function of the insurance level. However, empirical evidence suggest that it is rather the duration of unemployment benefit payments than the replacement rate that matters for the transition probability to employment, see e.g. Freeman (1998). 
payments to the workers who just lost their jobs. The number of inflows into unemployment equals the inflow rate times the employment rate in period 1 . Solving equation (2) for the tax in period 2 yields

$$
\tau_{2}=M \delta
$$

with

$$
M=s(f) \frac{a(f)+s(f)}{a(f)} \frac{a(1)}{a(1)+s(1)}=s(f) \frac{e_{1}}{e_{2}} .
$$

Voters out-of-the labor force shall receive no income, unless they live in a household with an employed voter. In this case they derive utility from an intra household public good that is provided by the bread-winner. Quite commonly I model the transfer that a person out-of-the labor force receives from an employed person with whom he shares the household as a public good (see Bergstrom (1997)). Here, the idea is that the employed household member derives utility from two goods, a private one $(c)$ to which he exclusively has access to, and a public good $(y)$ from which every household member enjoys utility. ${ }^{2}$ The amount of the public good, and thus intra household transfers is a choice of the employed household member. He allocates income $\left(1-\tau_{t}\right)$ between those two goods (both having a price of one by assumption) to maximize his utility

$$
U(c, y)=c^{\gamma}+y^{\gamma}
$$

with $0<\gamma<1$, given his budget and given the policies $\delta$ and $f$.

The timing of the model is the following (see also Figure 1): At $t=0$ workers are allocated to states $E, U$ and $O$. A share $\epsilon$ of voters who are not

\footnotetext{
${ }^{2}$ Examples for the public good are shared living space, television or shared automobile trips.
} 
attached to the labor market lives in a household with an employed voter. Thus, a household always consists of two persons. At time $t=0$ no institutions are in place, so that unemployed workers have zero income while the employed earn $w=1$. At the beginning of the following period $(t=1)$ the electorate votes on the two labor market institutions: job protection legislation and unemployment benefits. The institutions are implemented right after the election. Production takes place, with employed workers earning $\left(1-\tau_{1}\right)$ and unemployed workers receiving benefits $\delta$. At the end of period $t=1$ a firm might be hit by a shock. Workers are laid off and unemployed workers may find a job. In period $t=2$, production takes place with employed workers earning $\left(1-\tau_{2}\right)$ and unemployed workers receiving benefits $\delta$. Those who were unemployed in period 1 and did not find a job in period 2 (the long-term unemployed) shall not receive benefits. Time ends after period two elapsed.

I will proceed deriving the value functions for each state before introducing the political decision mechanism. Neglecting discounting, the value equation for the four types of agents write for the first period of production

$$
\begin{aligned}
V_{1}^{E} & =2\left(\frac{1}{2}\left(1-\tau_{1}\right)\right)^{\gamma}+s V_{2}^{U}+(1-s) V_{2}^{E} \\
V_{1}^{U} & =2\left(\frac{1}{2} \delta\right)^{\gamma}+a V_{2}^{E}+(1-a) V_{2}^{U_{L}} \\
V_{1}^{O_{F}} & =\left(\frac{1}{2}\left(1-\tau_{1}\right)\right)^{\gamma}+V_{2}^{O_{F}} \\
V_{1}^{O_{S}} & =0+V_{2}^{O_{S}} .
\end{aligned}
$$

The employed voter allocates his income in equal shares on the private good and the public good. At the end of the period after the shock hit, the employed voter may loose his job with $s(f)$ which yields utility $V_{2}^{U}$ in the 


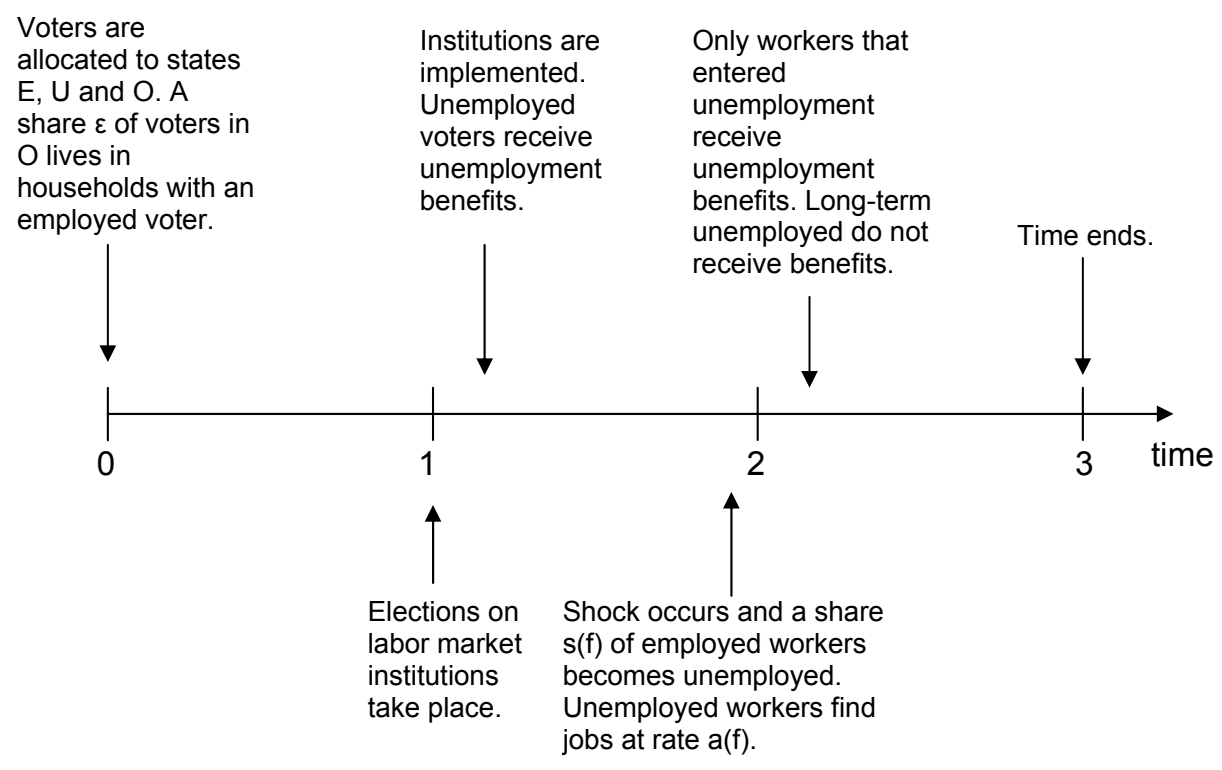

Figure 1: Sequence of events

second period or stay employed yielding utility $V_{2}^{E}$. The unemployed voter also allocates his income which is the unemployment benefits between the private and the public good. At the end of period 1 the unemployed voter finds a job at rate $a(f)$ in which case he will enjoy $V_{2}^{E}$ in the second period, or stay unemployed which will yield him utility $V_{2}^{U_{L}}$ of a long-term unemployed. If a person who is not attached to the labor market lives in a household with an employed voter he has access to the intra household public good. As by assumption those voters shall not enter employment or become eligible for unemployment benefits, their second period utility will be $V_{2}^{O_{F}}$ for certain. Those voters out-of-the labor force who do not live within households have zero income. 
The second period utilities for each type of voter are given by

$$
\begin{aligned}
V_{2}^{E} & =2\left(\frac{1}{2}\left(1-\tau_{2}\right)\right)^{\gamma} \\
V_{2}^{U} & =2\left(\frac{1}{2} \delta\right)^{\gamma} \\
V_{2}^{U_{L}} & =0 \\
V_{2}^{O_{F}} & =s\left(\frac{1}{2} \delta\right)^{\gamma}+(1-s)\left(\frac{1}{2}\left(1-\tau_{2}\right)\right)^{\gamma} \\
V_{2}^{O_{S}} & =0
\end{aligned}
$$

In period 2 the employed pay taxes $\tau_{2}$ so that their net income accrues to $\left(1-\tau_{2}\right)$ which again is equally allocated to the private and public good. Benefits to the (short-term) unemployed are $\delta$. The long term unemployed shall have zero income. The second period income from intra household public goods for the voter who is out of the labor force and lives in a household depends on the status of the household member that was employed in period one but might have lost his job at the end of period 1. Also in period 2 voters out-of-the labor force not living in households receive zero income. Inserting equations (8) to (12) into equations (4) to (7) yields utilities for the different types of voters in period 1 over the two institutions $f$ and $\delta$ as

$$
\begin{aligned}
V_{1}^{E} & =2\left(\frac{1}{2}\left(1-\tau_{1}\right)\right)^{\gamma}+s 2\left(\frac{1}{2} \delta\right)^{\gamma}+(1-s) 2\left(\frac{1}{2}\left(1-\tau_{2}\right)\right)^{\gamma} \\
V_{1}^{U} & =2\left(\frac{1}{2} \delta\right)^{\gamma}+a 2\left(\frac{1}{2}\left(1-\tau_{2}\right)\right)^{\gamma} \\
V_{1}^{O F} & =\frac{1}{2} V_{1}^{E} \\
V_{1}^{O S} & =0 .
\end{aligned}
$$

I turn to the political decision mechanism now. 


\section{$2.2 \quad$ The political sphere}

I employ a probabilistic voting model, see Persson and Tabellini (2000). Two office seeking parties $P=A, B$ shall simultaneously make proposals for the two policy variables EPL $\left(f_{P}\right)$ and the replacement rate $\left(\delta_{P}\right)$. The groups of voters shall have identical ideologies $\rho$ for the competing parties, uniformly distributed with density $\phi$ and zero means. In addition there is an overall ideological disposition denoted with $\eta$ which is also distributed uniformly and of mean zero, however with density $\psi$. A voter $i$ of type $J$, with $J=$ $E, U, O_{F}, O_{S}$ will vote for party $A$ if his utility fulfills

$$
V^{J}\left(q_{A}\right) \geq V^{J}\left(q_{B}\right)+\rho^{i J}+\eta
$$

with $q_{P}$ being the vector over the two policies $f_{P}$ and $\delta_{P}$. The timing is such that the two parties simultaneously make the policy proposals $q_{A}$ and $q_{B}$ at the end of period zero. Then the uncertainty with respect to the ideological dispositions of the voters is resolved. Elections are held and the winning party implements its announced policy at the beginning of period 1 .

Parties maximize their expected winning probability $p_{P}=P\left(\pi_{P}>1 / 2\right)$, where $\pi_{P}$ are the votes that party $P$ receives taking as given the policy of the competing party. The upshot of the probabilistic voting model is that the parties maximize a weighted welfare function in order to derive a policy proposal that gets them into office. In short, they maximize a function $W$ :

$$
W=e_{1} V_{1}^{E}\left(q_{P}\right)+u_{1} V_{1}^{U}\left(q_{P}\right)+\epsilon o V_{1}^{O_{F}}+(1-\epsilon) o V^{O_{S}}
$$

with respect to the policies $q_{P}(\delta, f)$. 


\section{Results}

Note, that the weights in equation (14) are independent from the choice of the labor market market insurance devices, due to the assumptions that unemployment benefits do not change the outflow rate from unemployment and job protection legislation only 'bites' at the end of period one after the shock occurred. The unemployment benefits and EPL are determined by the first order conditions

$$
\begin{gathered}
e_{1} \frac{\partial V_{1}^{E}}{\partial \delta}+u_{1} \frac{\partial V_{1}^{U}}{\partial \delta}+\frac{1}{2} \epsilon O \frac{\partial V_{1}^{E}}{\partial \delta}=0 \\
e_{1} \frac{\partial V_{1}^{E}}{\partial f}+u_{1} \frac{\partial V_{1}^{U}}{\partial f}+\frac{1}{2} \epsilon O \frac{\partial V_{1}^{E}}{\partial f}=0
\end{gathered}
$$

using $V_{1}^{E}=2 V_{1}^{O_{F}}$. As the utility of voters out-of-the labor force and not living in a family is not affected by the choice of insurance, only the marginal costs and benefits of the employed, unemployed and those out-of-the labor force living in a household determine the winning labor market policy. Inserting utilities and taking partial derivatives yields after rearranging the first order condition on the replacement rate as

$$
\begin{aligned}
& \left(e_{1}+\frac{1}{2} \epsilon O\right)\left(-\frac{u_{1}}{e_{1}} \frac{1}{\left(\frac{1}{2}\left(1-\delta \frac{u_{1}}{e_{1}}\right)\right)^{1-\gamma}}-(1-s) M \frac{1}{\left(\frac{1}{2}\left(1-\delta \frac{u_{1}}{e_{1}}\right)\right)^{1-\gamma}}+s \frac{1}{\left(\frac{1}{2} \delta\right)^{1-\gamma}}\right) \\
& +u_{1}\left(\frac{1}{\left(\frac{1}{2} \delta\right)^{1-\gamma}}-a M \frac{1}{\left(\frac{1}{2}\left(1-\delta \frac{u_{1}}{e_{1}}\right)\right)^{1-\gamma}}\right)=0 .
\end{aligned}
$$

The first order condition consists of two terms. One which is weighted with the share of the employed in period 1 and those living in a household with them. The other carries the unemployment rate in period 1 as a weight. An increase in the replacement rate decreases the utility of the former group 
as a voter in this group has to finance it in period one and should he stay employed also in period 2. In case he becomes unemployed he will profit from an increase in the replacement rate. An unemployed voter yields a marginal gain from an increase in the replacement rate in period 1 but should he find a job in period 2, he would have to carry the additional tax burden that comes with an increase in the replacement rate.

Inserting the utility functions and taking partial derivatives yields the first order condition on EPL for the political parties as

$$
\begin{aligned}
& \left(e_{1}+\frac{1}{2} \epsilon o\right)\left(-s_{f}\left(2\left(\frac{1}{2}(1-M \delta)\right)^{\gamma}-2\left(\frac{1}{2} \delta\right)^{\gamma}\right)-(1-s) K \delta \frac{\gamma}{\left(\frac{1}{2}(1-M \delta)\right)^{1-\gamma}}\right) \\
& +u_{1}\left(2 a_{f}\left(\frac{1}{2}(1-M \delta)\right)^{\gamma}-a K \delta \frac{\gamma}{\left(\frac{1}{2}(1-M \delta)\right)^{1-\gamma}}\right)=0,
\end{aligned}
$$

with $K=d M / d f$. A more rigid economy has a positive effect on the utility of the employed and those out-of-the labor force living with them. They oppose a more flexible economy as it would raise the likelihood of a job loss that would be accompanied by an income loss, given that income from work is higher than unemployment benefits. Suppose $K \geq 0$ which is fulfilled as long as the elasticity of employment in the second period with respect to the inflow rate is smaller or equal to one $\left(1 \geq\left(d e_{2} / d s\right)\left(s / e_{2}\right)\right)$. Then those individuals would also suffer from a more flexible economy because the higher costs of the unemployment benefit system would have to be covered by a higher tax rate should they stay employed. If $K \leq 0$, the case where more flexibility reduces the tax burden in period 2 , the tax effect would have the opposite sign. Turning to the marginal effects for the unemployed, one sees that a more flexible economy raises the utility of the unemployed as it 
increases the transition rate to employment. There is also a tax effect for the unemployed voter that he weighs with the likelihood of finding a job in period 2. Should the tax burden be reduced by a more flexible economy the marginal effect on the utility would be positive and vice versa.

In the following I derive conditions under which a higher share of household coverage $\epsilon$ yields a politico-economic equilibrium with more job protection relative to unemployment benefits.

For accomplishing this, let me first have a closer look at the choice of the unemployment benefit system given job protection. The first order condition (equation (15)) shows that the optimal choice of the competing parties is a weighted average of the choices of the employed and those living with them on the one hand, and the unemployed on the other hand. An unemployed voter's optimal choice of benefits given any level of job protection would be

$$
\delta_{u n}=\frac{1}{u_{1} / e_{1}+(a M)^{\frac{1}{1-\gamma}}}
$$

while an employed voter would prefer

$$
\delta_{e m p}=\frac{1}{u_{1} / e_{1}+\left(u_{1} / e_{1}+(1-s) M\right)^{\frac{1}{1-\gamma}}} .
$$

Obviously, an employed voter wants less insurance against unemployment given job protection than an unemployed. The unemployed voter's demand for insurance decreases as the economy becomes more flexible if a more flexible economy implies higher taxes in the second period $(K>0)$. This is the case because employment becomes relatively less attractive, so that the benefits can fall to make the unemployed voter equally off. How an employed voter's optimal choice reacts to a more flexible economy is dependent on 
the marginal effects of a change in flexibility on the likelihood of remaining employed and on the tax in the second period. Thus, while the first order condition on the unemployment benefits will clearly shift down in a diagram of $(\delta, f)$ as more voters out-of-the labor force live in a household with an employed, the slope of the first order condition is ambiguous.

Now let me hold the benefit level fixed, and analyze the preferences over EPL. A conflict of interest between the two groups arises in such a way that the employed and those living with them in a household would always choose a more rigid EPL than an unemployed voter if $K$ is sufficiently small in absolute terms. The intuition is the following: Assume $K$ was positive then a more flexible economy increases the tax burden in the second period. This would generate the effect that an employed voter would rather have a more rigid economy. The unemployed voter will prefer to have a more flexible economy as long as the tax effect is sufficiently small. If the tax effect was not sufficiently small there would be no point for him in making the economy more flexible in order to raise the likelihood of a transition to employment because income would be taxed away in the second period. If $K$ is negative, then the unemployed voter will want a fully flexible economy. The employed voter and his household member not being in the labor force will choose rigidity if $K$ is sufficiently small in absolute terms. If it was not, a more flexible economy would reduce the tax burden in the second period so heavily that even an employed voter would want a more flexible economy. Thus, for $K$ being sufficiently small in absolute terms the optimal choice of the political parties will be such that more EPL will arise as the ratio of voters out-of-the labor force receiving transfers increases, given any 
level of unemployment benefits. As is the case with the first order condition on benefits, the slope of the first order condition on job protection is also ambiguous. $^{3}$

That the comparative statics of the model yield higher EPL levels relative to unemployment benefits as the share of voters out-of-the labor force living in households increases can be illustrated by a numerical exercise. For the example the inflow and outflow rates have been specified as

$$
\begin{gathered}
s=c+b f^{\beta} \\
a=d+h f^{\alpha}
\end{gathered}
$$

with $c, b, \beta, d, h, \alpha>0$. Figure 2 shows the first order conditions for $\epsilon=0$ (solid line) and $\epsilon=1$ (dashed line). As the share of voters out-of-the labor force living in a household with an employed increases, unemployment benefits decrease and EPL becomes more stringent. Note, that the parameters which were chosen for the inflow and outflow rates yield reasonable values for the endogenous variables. Take the case where there is full coverage of voters out-of-the labor force by household transfer $(\epsilon=1)$. With a quarterly calibration and $a \approx 0.5$ average duration of unemployment is about half a year and the average duration of a job is approximately five years $(s \approx 0.05)$. The unemployment rate defined as unemployed divided by the sum of unemployed and employed in the second period of production is $u_{2} \approx 0.09$. Remember that the share of voters out of the labor force in the numerical example is $o=0.3$. Thus the employment rate defined as the employed divided by the whole population becomes approximately 0.7 .

\footnotetext{
${ }^{3}$ For the numerical example that follows I verified the second order conditions for a maximum.
} 


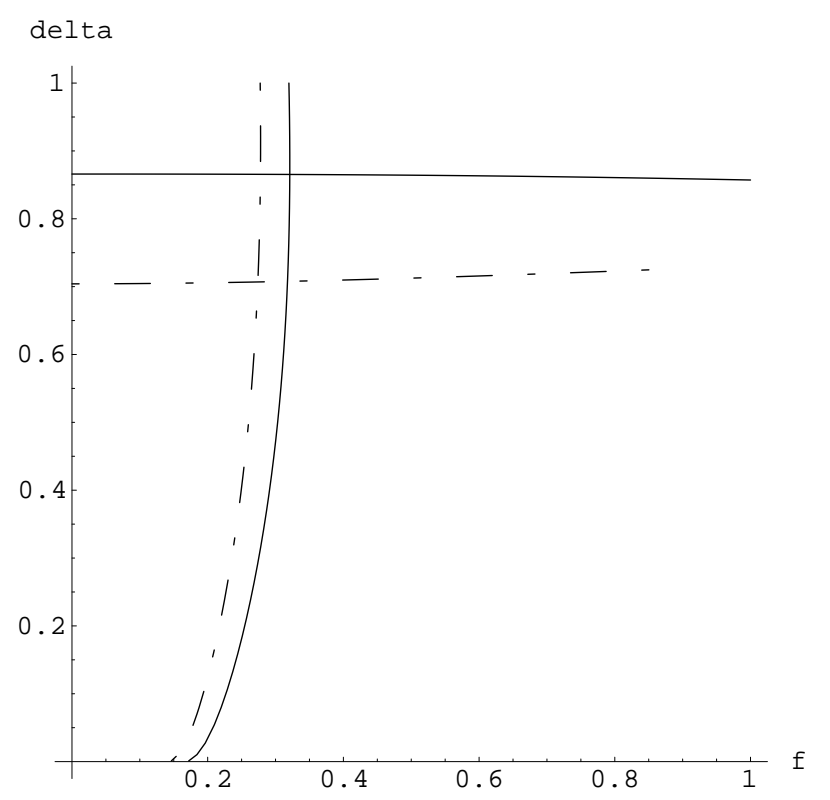

Figure 2: Politico-economic equilibria; $c=0.05, b=0.05, \beta=2, \alpha=1, d=$ $0.5, h=0.1, o=0.3$; dashed line represents case in which $\epsilon=1$; solid line represents case in which $\epsilon=0$.

The following section presents empirical evidence supporting the explanation of the trade-off between the two insurance devices.

\section{Evidence}

Figure 3 plots a measure of the trade-off of the two insurance devices against an indicator that captures the role of households as a means of an income source. The vertical axis is the ratio of the replacement rate and the OECD 
index for the strictness of EPL. ${ }^{4}$ Thus, higher values indicate that in those countries there is more unemployment benefit provision relative to EPL. The variable on the horizontal axis is the ratio of the inactivity rate among individuals and the non-employment rate among households (see OECD (2001)). Higher ratios of inactivity of individuals to non-employment rates of households imply that in those countries the household plays a larger role in providing insurance to inactive individuals. Suppose, for example, that all countries had the same inactivity rate. Then, the ratio would be larger for those countries where the household provides protection - measured by smaller rates of non-employment among households. The indicator for the trade-off draws on data from the end of the 90 's, and the indicator that refers to which extent households provide a means of insurance is from the year 1996. This is done to account for possible endogeneity of the market outcome. With a time lag on the inactivity and non-employment rates among households it is more stringent to argue that market outcomes cause institutional choices. Consistent with the main proposition of the model there is a negative correlation. Those countries in which the household is less of a means for transferring income also have higher unemployment benefits relative to EPL. The correlation coefficient is -0.50 and statistically significant at $5 \%$.

Former empirical work on labor market institutions has used other variables to explain unemployment insurance provision (but not the mix of insurance devices.) In a regression model (see table 1) I take into account

\footnotetext{
${ }^{4}$ The net replacement rate indicator stems from the OECD, Benefits and Wages and is the average for four family types, over a five-year period and two earnings levels in 1999 (www.oecd.org/els/social/workincentives). The EPL indicator can be found in OECD (1999), Table 2.5, Version 2.
} 


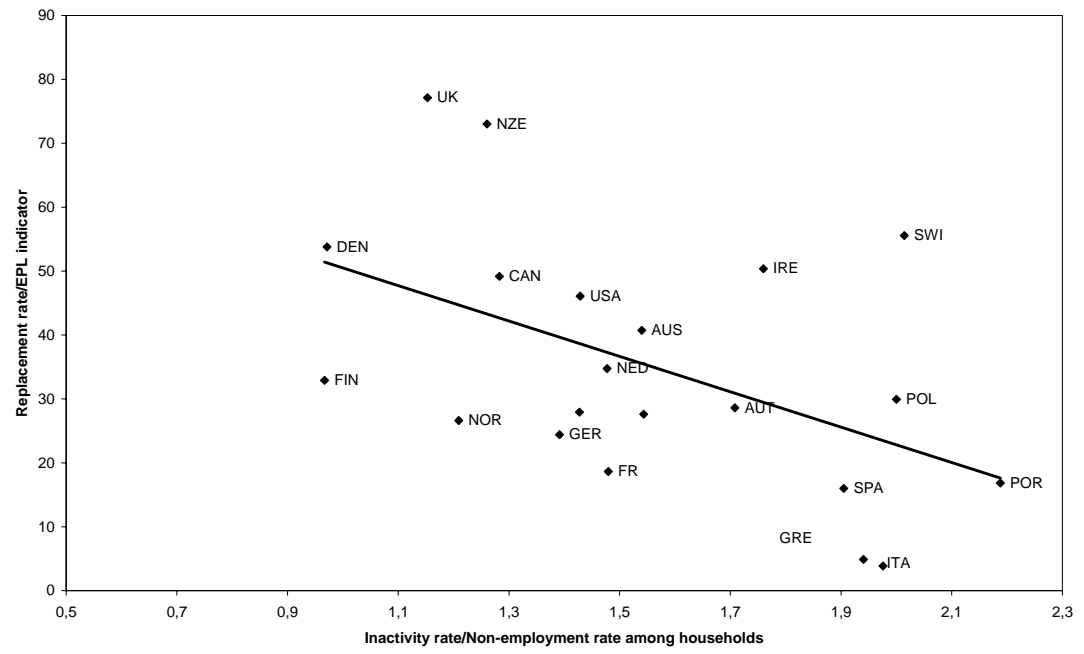

Figure 3: Modes of insurance in the labor market over inactivity rate divided by non-employment rate among households

other potential explanations of the trade-off between the two insurance devices. For example, Agell (2002) included variables measuring the size of the population and the openness of countries. Country size may matter if there are economies of scale such as fixed costs to the creation of institutions, which could arise when a workable administrative system of unemployment benefit compensations has to be established first (see Alesina and Wacziarg (1998)). Such a line of reasoning could apply in our case if costs for installing one over the other institution differ. The justification to include an openness variable in the regression may be that workers in countries that are more exposed to the world market may face a larger risk of becoming unemployed. Therefore, as was argued, citizens in those countries may opt for larger governments as an insurance device (see Rodrik (1998)). In our 
case, voters might opt for a mix of insurance devices that is more adaptable to the needs of a changing world economy. Unemployment insurance over job protection could be preferred as the latter would slow down the reallocation of resources slowing down growth. As figure 3 shows a clustering of countries from southern Europe with lower GDP per capita, a control for income might also be of interest. Finally, I controlled for the skill composition with a variable measuring the share of workers with a lower secondary education in the population aged 15 to $64 .^{5}$

I ran regressions of the measure of the insurance mix on the ratio of the inactivity rate over the non-employment rate among households controlling sequentially for openness, GDP per capita, size of countries, and the skill composition. Contrary to the ratio of the inactivity rate to the nonemployment rate among households none of the controls was significant, see table 1. Altogether, those OLS regressions support the argument that the choice of insurance devices in the labor market is a function of whether the family serves as an alternative insurance device.

\section{Conclusions}

In a cross country perspective modes of insurance in the labor market differ. There occurs to be a robust trade-off between EPL and unemployment insur-

\footnotetext{
${ }^{5}$ The control variables' data refer to the year 1996, except for the variable measuring the skill composition which refers to the year 1999 due to an insufficient number of observations for the earlier year. The data on the skill composition can be found at: http://www1.oecd.org/scripts/cde/members/lfsindicatorsAuthenticate.asp, all other controls are taken from Penn World Data.
} 
Table 1: OLS regressions

\begin{tabular}{|c|c|c|c|c|c|}
\hline \multicolumn{6}{|c|}{ Dependent variable: Modes of insurance } \\
\hline Constant & 78.16 & 72.27 & 68.59 & 78.63 & 73.17 \\
\hline & $(0.000)$ & $(0.002)$ & $(0.067)$ & $(0.000)$ & $(0.001$ \\
\hline \multirow[t]{2}{*}{ Inact. rate divided by emp. rate } & -27.66 & -27.21 & -25.53 & -27.75 & -22.98 \\
\hline & $(0.022)$ & $(0.026)$ & $(0.069)$ & $(0.025)$ & $(0.054)$ \\
\hline \multirow[t]{2}{*}{ Openness } & & 0.08 & & & \\
\hline & & $(0.528)$ & & & \\
\hline \multirow[t]{2}{*}{ GDP per capita } & & & 0.00 & & \\
\hline & & & $(0.755)$ & & \\
\hline \multirow[t]{2}{*}{ Population size } & & & & 0.00 & \\
\hline & & & & $(0.901)$ & \\
\hline \multirow[t]{2}{*}{ Skill composition } & & & & & -0.200 \\
\hline & & & & & $(0.718)$ \\
\hline $\mathrm{N}$ & 21 & 21 & 21 & 21 & 20 \\
\hline adj. $R^{2}$ & 0.21 & 0.17 & 0.18 & 0.17 & 0.14 \\
\hline
\end{tabular}

p-values are in () 
ance, such that countries show either a relatively high level of EPL and low benefit levels or vice versa. I argued that where countries locate on this tradeoff can be explained by the variation in intra household transfers to those voters who are out-of-the labor force. The driving force is that voters who are not attached to the labor market but live in households with employed workers have a preference for more EPL relative to unemployment insurance which competing parties take into account when making policy proposals. Voters not attached to the labor market but living in a household have a vested interest in protecting the job of the employed household member out of which the intra household transfers are paid given unemployment benefit levels. Given job protection, voters who are out-of-the labor force and covered by household transfers want relatively little unemployment benefits as a more generous unemployment benefit system would lower the transfers they receive from the employed household member. The explanation of the insurance mix in the labor market through variation in the household coverage of voters out-of-the labor force finds support in cross country data.

\section{Acknowledgements}

I would like to thank my colleagues in the research unit on labor market policy and employment, and the participants at the institute seminar of the Deutsches Institut für Wirtschaftsforschung, in particular Viktor Steiner, and at the economics seminar of the Social Science Center (WZB) for their suggestions. I am responsible for all remaining errors. 


\section{References}

Agell, J. (2002): "On the determinants of labour market institutions: rent seeking vs. social insurance," German Economic Review, 3, 107-135.

Alesina, A. And R. Wacziarg (1998): "Openness, country size and government," Journal of Public Economics, 69, 305-321.

Algan, Y. And P. Cahuc (2004): "Job protection: The macho hypothesis," IZA Discussion Paper No. 1192.

Bergstrom, T. (1997): "A survey of theories of the family," in Handbook of Population and Family Economics, ed. by M. Rosenzweig and O. Stark, Amsterdam: Elsevier, vol. 1A, 21-79.

Bertola, G. And T. Boeri (2002): "EMU labour markets two years on: microeconomic tensions and institutional evolution," in EMU and Economic Policy in Europe, ed. by M. Buti and A. Sapir, Edward Elgar, 249-280.

Boeri, T., J. Conde-Ruiz, And V. Galasso (2004): "Cross-skill redistribution and the trade-off between unemployment benefits and employment protection," CEPR Discussion Paper 4711.

Brugiavini, A., J. Conde-Ruiz, and V. Galasso (2003): "Social security, private transfers and voting behaviour: the Italian case," in Annual Report on Monitoring Italy, ed. by ISAE, 187-232.

Buti, M., L. Pench, And P. Sestito (1998): "Contending theories and 
institutional complexities," European University Institute, Florence, Policy Papers, RSC No. 98/1.

Commission, E. (2003): 2003 Adopted Employment Guidelines.

DiTella, R. and R. J. MacCulloch (2002): "The determination of unemployment benefits," Journal of Labor Economics, 20, 404-434.

FogLi, A. (2000): "Endogenous labor market rigidities and family ties," Discussion Paper, New York University.

Freeman, R. (1998): "War of the models: which labour market institutions for the 21st century?" Labour Economics, 5, 1-24.

Hassler, J., J. R. Mora, K. Storesletten, and F. Zilibotti (2005): "A positive theory of geographic mobility and social insurance," International Economic Review, 46, 263-303.

LAItNeR, J. (1997): "Intergenerational and interhousehold economic links," in Handbook of Population and Family Economics, ed. by M. Rosenzweig and O. Stark, Amsterdam: Elsevier, vol. 1A, 189-238.

McElroy, M. (1985): "The joint determination of household membership and market work: The case of young men," Journal of Labor Economics, 3, 293-316.

Neugart, M. (2005): "Unemployment insurance: the role of electoral systems and regional labor markets," European Journal of Political Economy, forthcoming. 
OECD (1999): Employment Outlook 1999, Paris: OECD. (2001): Employment Outlook 2001, Paris: OECD.

Persson, T. and G. Tabellini (2000): Political Economics, Explaining Economic Policy, MIT Press.

RoDrIK, D. (1998): "Why do more open economies have bigger governments," Journal of Political Economy, 105, 997-1032.

RosenzWeig, M. And K. Wolpin (1993): "Intergenerational support and the life-cycle incomes of young men and their parents: Human capital investments, coresidence, and intergenerational financial transfers," Journal of Labor Economics, 11, 84-112.

SAInT-PAul, G. (1996): "Exploring the political economy of labour market institutions," Economic Policy, 23, 265-315.

_ (2002): "The political economy of employment protection," Journal of Political Economy, 110, 672-704.

Wright, R. (1986): "The redistributive roles of unemployment insurance and the dynamics of voting," Journal of Public Economics, 31, 377-399. 